\title{
Nanobodies targeting conserved epitopes on the major outer membrane protein of Campylobacter as potential tools for control of Campylobacter colonization
}

\author{
Charlotte Vanmarsenille 1,2,3,4, Inés Díaz del Olmo 1,2,3 , Jelle Elseviers ${ }^{5}$, Gholamreza Hassanzadeh Ghassabeh ${ }^{5}$, \\ Kristof Moonens ${ }^{1,2}$, Didier Vertommen ${ }^{6}$, An Martel $^{4}$, Freddy Haesebrouck ${ }^{4}$, Frank Pasmans ${ }^{4}$, \\ Jean-Pierre Hernalsteens ${ }^{3}$ and Henri De Greve ${ }^{1,2^{*}}$
}

\begin{abstract}
Campylobacter infections are among the most prevalent foodborne infections in humans, resulting in a massive disease burden worldwide. Broilers have been identified as the major source of campylobacteriosis and reducing Campylobacter loads in the broiler caeca has been proposed as an effective measure to decrease the number of infections in humans. Failure of current methods to control Campylobacter in broilers stresses the urgency to develop novel mitigation measures. We obtained six nanobodies with a broad specificity, that recognize strains belonging to the two most relevant species, Campylobacter jejuni and Campylobacter coli. The target of the nanobodies was identified as the major outer membrane protein, a porin that contributes to bacterial virulence and viability. Multimerization of the nanobodies led to agglutination of $C$. jejuni cells, which may affect colonization in the chicken gut. These Campylobacter-specific nanobodies may be useful to develop a strategy for preserving chickens from Campylobacter colonization.
\end{abstract}

\section{Introduction}

Worldwide, Campylobacter is one of the most common causes of gastroenteritis $[1,2]$. Less than 500 bacteria are required to establish infection, hence small amounts present in food or water can cause human infections [3]. The Campylobacter species mostly associated with infection, in both industrialized and developing countries, are C. jejuni and C. coli [4]. Typical clinical symptoms of Campylobacter infections in humans are abdominal cramps, diarrhoea and fever. Usually, Campylobacter enteritis is a self-limiting disease and antibiotic treatment is only necessary in persistent cases [5, 6]. However, infections with $C$. jejuni can lead to severe complications like the Guillain-Barré syndrome, a

${ }^{*}$ Correspondence: henri.de.greve@vub.be

${ }^{2}$ Structural Biology Brussels, Vrije Universiteit Brussel, Pleinlaan 2,

1050 Brussels, Belgium

Full list of author information is available at the end of the article paralyzing neuropathological disease $[7,8]$. The favoured environmental reservoir of $C$. jejuni is the intestinal tract of poultry, that is considered the natural host of $C$. jejuni. The elevated body temperature of chickens (i.e. $42{ }^{\circ} \mathrm{C}$ ) corresponds to the optimal growth temperature of $C$. jejuni, which makes them an outstanding reservoir for the bacteria [9]. Campylobacter mainly colonizes the mucus layer of the intestinal tract and is abundantly present in the caecum. Up to $10^{9} \mathrm{CFU} / \mathrm{g}$ faecal content can be reached $[10,11]$. At slaughter age, up to $80 \%$ of the flocks worldwide are contaminated with Campylobacter bacteria. Consumption and handling of contaminated poultry meat or carcasses are the most common causes of Campylobacter infections in humans [12-15].

Since poultry plays such an important role in transmission, a decrease of the colonization of poultry by Campylobacter will lead to a reduction of Campylobacter-related enteritis cases in humans [16]. Hygiene and biosafety play an essential role in the control of Campylobacter 
infections in poultry, but these methods alone are not sufficiently effective and must be complemented with novel control approaches [17]. Still, no effective control measures are available to prevent or reduce the prevalence of C. jejuni in poultry during primary production $[18,19]$. The addition of antibiotics to animal feed is not acceptable, as this leads to an increasing number of resistant strains which has serious consequences for the treatment of humans [20,21]. Therefore, a wide range of alternative approaches have been screened. An effective vaccine has not yet been developed and the use of fatty acids, bioactive plant additives or probiotics did not lead to the desired in vivo effect [22-24]. Other alternatives, like the use of bacteriophages and bacteriocins, are more promising, however, more research is required [24-26]. Maternal anti-Campylobacter antibodies protect young chicks during the first 2-3 weeks $[27,28]$. Consequently, the use of maternal antibodies, isolated from eggs of immunized hens, has been assessed for the passive immunization of infected chickens. The results were promising for the use as therapeutic treatment $[29,30]$.

In this study, we describe the isolation and characterization of nanobodies $(\mathrm{Nb})$ recognizing multiple Campylobacter strains. Nanobodies are the antigen-binding domains of heavy chain antibodies found in Camelidae [31]. They possess a number of advantages over antibodies, which makes their use attractive for diagnostic and therapeutic purposes. Nanobodies interact with their antigen with high affinity and specificity, they are highly stable and soluble and can be expressed in microbial expression systems [32, 33]. The nanobodies isolated in this study bind with the major outer membrane protein (MOMP). Outer membrane proteins (OMP) play a major role in adhesion and invasion during Campylobacter infections [34]. Therefore nanobodies targeting these proteins could be interesting tools for the development of a control strategy. One of the outer membrane proteins important for virulence of Campylobacter is the MOMP, encoded by the porA-gene. MOMP is a conserved trimeric $\beta$-barrel porin involved in adhesion [35]. The porin is also essential for viability of Campylobacter, as its deletion results in a lethal phenotype [36, 37]. It is required for structural organization and stabilization of the outer membrane and it makes the diffusion possible of compounds, like nutrients and antibiotics, across the membrane [38, 39].

\section{Materials and methods}

\section{Bacterial strains and growth condition}

The bacterial strains that were used in this study are indicated in Table 1. C. jejuni KC40 was used as a reference strain. C. jejuni was grown on Nutrient Broth Nr.2, solidified with 1.5\% agar (NB2, CM0067; Thermo Fisher
Table 1 Bacterial strains used in this study

\begin{tabular}{|c|c|c|}
\hline Species & Strain & Source \\
\hline \multirow[t]{23}{*}{ C. jejuni } & KC40 & Environment chicken ${ }^{a *+}$ \\
\hline & $7 P-6.12$ & Chicken $^{\mathrm{a}+}$ \\
\hline & $10 C-6.1$ & Chicken $^{a+}$ \\
\hline & $10 K F-1.16$ & Chicken $^{\text {a+ }}$ \\
\hline & $10 K F-4.12$ & Chicken $^{a+}$ \\
\hline & 10VTDD-8 & Chicken $^{a+}$ \\
\hline & KC59.1 & Chicken $^{a *}$ \\
\hline & KC64.1 & Chicken $^{a *}$ \\
\hline & KC67.1 & Chicken $^{a *}$ \\
\hline & KC84.1 & Chicken $^{a *}$ \\
\hline & KC96.1 & Chicken $^{\mathrm{a} *}$ \\
\hline & KC101 & Environment chicken ${ }^{a *}$ \\
\hline & Cam12/0214 & Human $^{b}$ \\
\hline & Cam12/0231 & Human ${ }^{b}$ \\
\hline & Cam12/0146 & Human $^{\text {b }}$ \\
\hline & Cam12/0152 & Human $^{b}$ \\
\hline & Cam12/0173 & Human ${ }^{b}$ \\
\hline & Cam12/0197 & Human ${ }^{b}$ \\
\hline & Cam12/0156 & Human $^{b}$ \\
\hline & Cam12/0190 & Human $^{b}$ \\
\hline & Cam12/0202 & Human $^{b}$ \\
\hline & Cam12/0222 & Human $^{b}$ \\
\hline & Cam12/0183 & Human $^{b}$ \\
\hline \multirow[t]{5}{*}{ C. coli } & $52 / P$ & Chicken ${ }^{c}$ \\
\hline & $70 / P$ & Chicken $^{c}$ \\
\hline & $\mathrm{K} 43 / 5$ & Chicken $^{c}$ \\
\hline & KC7 & Chicken $^{c}$ \\
\hline & MB3361 & Chicken $^{c}$ \\
\hline \multirow[t]{3}{*}{ E. coli } & TG1 & {$[68]$} \\
\hline & $\mathrm{DH} 5 \mathrm{a}$ & [69] \\
\hline & WK6 & [70] \\
\hline
\end{tabular}

* The fla-DGGE analysis is described in Najdenski et al. [51].

+ The MLST results are described in Hermans et al. [30].

a Isolates obtained from a poultry farm or a slaughterhouse, provided by Dr. Marc Heyndrickx (Institute for Agricultural and Fisheries Research, Technology and Food Science Unit-Food Safety, Melle, Belgium).

b Clinical isolates obtained from faeces of infected patients, provided by Dr. D. Martiny (Microbiology Department, Iris-lab, Brussels, Belgium). MLST analysis showed that the isolates belong to different clonal complexes (CC-21, CC-464, CC-21, CC-206, CC-48, CC-45) (D. Martiny, personal communication).

c Isolates obtained from chickens, provided by Dr. Marc Heyndrickx (Institute for Agricultural and Fisheries Research, Technology and Food Science Unit-Food Safety, Melle, Belgium).

Scientific) under microaerobic conditions (Oxoid $^{\mathrm{TM}}$ CampyGen ${ }^{\mathrm{T}}$, Thermo Fisher Scientific) at $42{ }^{\circ} \mathrm{C}$ for $48 \mathrm{~h}$. Escherichia coli strains were cultured on LB medium (Duchefa Biochemie), supplemented with the appropriate antibiotics if necessary. 


\section{Phage library construction and selection of anti-Campylobacter nanobodies}

A detailed protocol for immunization, generation of a nanobody library and selection by phage panning has been described [40]. C. jejuni KC40 cells were heat-inactivated at $55^{\circ} \mathrm{C}$ for $1 \mathrm{~h}$. An alpaca was injected six times with $1.6 \times 10^{8}$ inactivated C. jejuni KC40. Peripheral lymphocytes were isolated from the blood of the immunized alpaca, from which RNA was isolated and converted to cDNA [40]. PCR on the cDNA was used to amplify the sequences encoding the variable domains of heavy chain antibodies. The resulting PCR fragments were cloned in the phage display vector pHen4 [41] and transformed in E. coli TG1 cells. Phage display was used for the selection of Campylobacter-specific nanobodies from the immune library. The phage library was panned twice against an outer membrane extract. Binding phages from the second panning were eluted and used for infection of $E$. coli TG1. From 95 individual E. coli TG1 transformants, a periplasmic extract was prepared and used in an ELISA, to confirm their specificity for the outer membrane extract of Campylobacter. Subsequently, the nanobodyencoding genes from 21 positive clones were amplified from the pHen 4 plasmid for sequencing.

\section{Tagging of the nanobodies}

The nanobodies were cloned in the pHen6C vector [42], designed for the introduction of a histidine-tag (His-tag) at the C-terminus. PCR was performed using In-Fusion primers IF-NB1 (5'-TGGCCCAGGTGCAGCTGCAGGAGTCTGGAG-3') and IF-NB2 (5'-TGAGGAGACGGTGACCTGGGTCC-3'). For the introduction of the PCR fragments in the pHen6C, the vector was digested with PstI and BstEII and the cloning was carried out with the In-Fusion ${ }^{\circledR}$ HD Cloning Kit (Takara Bio USA, Inc).

For the construction of the strep-tagged nanobodies, the pHen6C derivatives encoding the His-tagged nanobodies were used. The His-tag was removed using the BstEII and EcoRI restriction enzymes. The streptag was introduced by ligation of annealed oligo's (5'-GTCACCGTCTCCTCATGGAGCCACCCGCAGTT CGAAAAATAAGTTTAAACTAC-3' and 5'-AATTTAG TTTAAACTTATTTTTCGAACTGCGGGTGGCTCCA TGAGGAGAC G-3') in the linearized pHen6C vectors.

The resulting constructs were transformed into $\mathrm{CaCl}_{2}$-competent E. coli $\mathrm{DH} 5 \alpha$ [43] and transformants were selected on LB-agar plates supplemented with $100 \mu \mathrm{g} / \mathrm{mL}$ carbenicillin. Colonies were screened by PCR with the primers FP24 (5'-CGCCAGGGTTTTCCCAGTCACGAC-3 $\left.{ }^{\prime}\right)$ and RP24 (5'-AGCGGATAACAATTTCACACAGGA-3'). PCR-positive colonies were sequenced to confirm that the constructs were correct.

\section{Expression and purification of anti-Campylobacter nanobodies}

Clones encoding C-terminally His-tagged anti-Campylobacter nanobodies were introduced in E. coli WK6 for expression and purification. The bacterial cells were grown at $37{ }^{\circ} \mathrm{C}$ in LB medium supplemented with carbenicillin $(100 \mu \mathrm{g} / \mathrm{mL})$. When $\mathrm{OD}_{660 \mathrm{~nm}} 0.6-0.8$ was reached, nanobody expression was induced at $30{ }^{\circ} \mathrm{C}$ by adding $1 \mathrm{mM}$ isopropyl $\beta-\mathrm{D}-1$ thiogalactopyranoside (Thermo Fisher Scientific). After overnight incubation, the periplasmic content was extracted and the nanobodies were purified.

His-tagged nanobodies were purified by nickel-affinity chromatography using HisTrap HP columns (GE Healthcare Life Sciences). The columns were equilibrated and washed with $20 \mathrm{mM}$ Tris- $\mathrm{HCl}, 1 \mathrm{M} \mathrm{NaCl}, \mathrm{pH}$ 8.0. Nanobodies were eluted using a linear gradient to $1 \mathrm{M}$ imidazole. The eluted protein fractions were analysed by SDS-PAGE, using 12.5\% acrylamide gels stained with Coomassie blue dye. The PageRuler ${ }^{\mathrm{TM}}$ Prestained Protein Ladder (Thermo Fisher Scientific) is used as a molecular weight marker. Fractions containing pure nanobodies were pooled and dialyzed against phosphate-buffered saline (PBS).

Strep-tagged nanobodies were purified using StrepTrap HP columns (GE Healthcare Life Sciences). These were equilibrated and washed with $100 \mathrm{mM}$ Tris- $\mathrm{HCl}$, $150 \mathrm{mM} \mathrm{NaCl}, 1 \mathrm{mM}$ EDTA, pH 8.0 and nanobodies were eluted with a linear gradient to $2.5 \mathrm{mM}$ desthiobiotin. Fractions containing pure nanobodies were dialyzed against PBS.

\section{Whole-bacterial cell ELISA}

The interaction of the purified nanobodies, with different $C$. jejuni and $C$. coli isolates was assessed by means of a whole-cell ELISA. The bacteria were grown on NB2agar plates and after $48 \mathrm{~h}$ the cells were harvested from the plates with PBS. The bacterial cells were centrifuged at $3600 \mathrm{~g}$ for $15 \mathrm{~min}$ and washed in PBS. Bacterial cells were fixed with $2.5 \%$ (v/v, final concentration) of methanol-stabilized 37\% formaldehyde solution (Merck), followed by incubation for $100 \mathrm{~min}$ at $42{ }^{\circ} \mathrm{C}$. Afterwards, the fixed bacterial cells were pelleted by centrifugation. The pellet was resuspended in coating buffer $(150 \mathrm{mM}$ $\mathrm{Na}_{2} \mathrm{CO}_{3}, 46 \mathrm{mM} \mathrm{NaHCO}$ ) and the $\mathrm{OD}_{660}$ was adjusted to 0.3 . From the suspension, $100 \mu \mathrm{L}$ per well was used to coat a 96-well plate. After overnight incubation at $4{ }^{\circ} \mathrm{C}$, the plates were washed five times with $\mathrm{PBS}+0.05 \%$ Tween ${ }^{\circledR}-20$. To reduce nonspecific interactions, $200 \mu \mathrm{L}$ $5 \%(\mathrm{w} / \mathrm{v})$ bovine serum albumin (BSA) was used per well and incubated for $2 \mathrm{~h}$. Subsequently, the wells were washed five times and $100 \mu \mathrm{L} /$ well of the anti-Campylobacter nanobodies $(50 \mu \mathrm{g} / \mathrm{mL})$ was added, followed by 
$1 \mathrm{~h}$ incubation at room temperature. Afterwards, mouse anti-Histidine tag monoclonal antibody (1:1000) (AbD Serotec) and goat anti-mouse IgG conjugated to alkaline phosphatase (AP) (1:5000) (Sigma-Aldrich) were added consecutively. The ELISA was developed by addition of $2 \mathrm{mg} / \mathrm{mL}$ para-nitrophenyl phosphate (p-NPP) in ELISA buffer (100 mM Tris-HCl, pH 9.5, $5 \mathrm{mM} \mathrm{MgCl}_{2}, 100 \mathrm{mM}$ $\mathrm{NaCl}$ ). The OD was read at $405 \mathrm{~nm}$.

\section{Preparation of outer membrane extract}

Campylobacter jejuni KC40 was cultured on NB2-agar plates and the bacterial cells were resuspended in $10 \mathrm{mM}$ HEPES pH 7.4. The cells were lysed by passing the culture twice through the Cell Cracker (Glen Creston, Stanmore, VK, UK) at 1000 psi (pound-force per square inch) at $4{ }^{\circ} \mathrm{C}$. To remove cell debris, the disrupted cell suspension was centrifuged at $12000 \mathrm{~g}$ at $4{ }^{\circ} \mathrm{C}$ for $10 \mathrm{~min}$. The further isolation of the outer membranes in the supernatant was performed as described [44], with the exception that, after the sarkosyl treatment, the membranes were centrifuged for $30 \mathrm{~min}$ instead of $1 \mathrm{~h}$. The obtained OMPs were stored in $20 \mathrm{mM}$ HEPES pH 7.4 at $-20{ }^{\circ} \mathrm{C}$.

\section{Purification of the MOMP}

The MOMP was purified from a total membrane extract. The outer membrane proteins were incubated in the presence of $0.3 \%$ n-octylpolyoxyethylene (octyl-POE) for $20 \mathrm{~min}$ at $4{ }^{\circ} \mathrm{C}$. The insoluble proteins were pelleted by centrifugation at $100000 \mathrm{~g}$ for $1 \mathrm{~h}$. This step was repeated once, followed by two successive extraction steps with $0.5 \%$ octyl-POE. The obtained fractions were further purified using anion-exchange chromatography. A Resource Q column (GE Healthcare Life Sciences) was equilibrated with $20 \mathrm{mM}$ sodium phosphate buffer $\mathrm{pH}$ 6.0 supplemented with $0.6 \%$ octyl-POE and the extracted proteins were loaded on the equilibrated column. Elution was achieved using a linear gradient to $1 \mathrm{M} \mathrm{NaCl}$. The eluted fractions were analysed by SDS-PAGE, stained with Coomassie blue dye. Pure fractions were pooled and dialysed against $20 \mathrm{mM}$ sodium phosphate buffer $\mathrm{pH} 7.6$ supplemented with $0.6 \%$ octyl-POE.

\section{Interaction of nanobodies and outer membrane proteins in ELISA}

The interaction of the nanobodies with the outer membrane extract and the purified MOMP was investigated using ELISA. Native or denatured outer membrane extract and purified MOMP were coated in a 96-well plate at a concentration of $1 \mu \mathrm{g} / \mathrm{mL}$. The ELISA was further carried out as described above. For the ELISA with outer membrane extract, tenfold serial dilutions were made of the anti-Campylobacter nanobodies, starting from $50 \mu \mathrm{g} / \mathrm{mL}$.

\section{Pull-down assay for antigen determination}

To isolate OMP-Nb complexes, the Dynabeads ${ }^{\circledR}$ His-Tag Isolation and Pulldown kit (Thermo Fisher Scientific) was used. Twenty microliter of nanobodies $(1.0 \mathrm{mg} / \mathrm{mL})$ was added to $500 \mu \mathrm{L}$ of the isolated outer membrane proteins $(1.2 \mathrm{mg} / \mathrm{mL})$ and the mixture was incubated for $2 \mathrm{~h}$ at $4{ }^{\circ} \mathrm{C}$ on a roller. The His-tagged nanobodies interact with the $\mathrm{Co}^{2+}$-coated magnetic beads. The procedure was followed as described in the manual, with the exception that the samples containing the OMP-Nb complexes where incubated overnight with the Dynabeads at $4{ }^{\circ} \mathrm{C}$. An SDS-PAGE was performed on the eluted complexes and the gel was stained with the SilverQuest ${ }^{\mathrm{TM}}$ Silver Staining Kit (Thermo Fisher Scientific). The relevant protein bands were excised from the gel, destained and digested with trypsin for further analysis by liquid chromatography-tandem mass spectrometry (LC-MS/MS) as described [45].

Western blotting was performed on denatured and non-denatured proteins. The non-denatured samples, were run on a $12.5 \%$ acrylamide gel in running buffer composed of $14.4 \mathrm{~g}$ glycine, $3.03 \mathrm{~g}$ Tris and $0.250 \mathrm{~g}$ SDS per litre. After electrophoresis, the proteins were either transferred to a polyvinylidene difluoride (PVDF) membrane, activated with methanol, or stained with Coomassie blue dye. After transfer, the membrane was washed five times with PBS $+0.2 \%$ Triton X-100, followed by an incubation of $1 \mathrm{~h}$ at $4{ }^{\circ} \mathrm{C}$ with blocking buffer (PBS $+10 \%$ milk powder). The washing step was repeated in between every incubation step. The washed PVDF membrane was then incubated with $5 \mu \mathrm{g} / \mathrm{mL}$ anti-Campylobacter nanobody, diluted in PBS $+0.2 \%$ Triton X-100 $+5 \%$ milk powder for $1 \mathrm{~h}$ at $4{ }^{\circ} \mathrm{C}$. For the detection of the His-tagged nanobodies, a mouse anti-Histidine tag monoclonal antibody (1:1000) (AbD Serotec) was added and incubated for $1 \mathrm{~h}$ at $4{ }^{\circ} \mathrm{C}$. The western blot was developed with a goat anti-mouse IgG conjugated to alkaline phosphatase (AP) (1:5000) (Sigma-Aldrich). After $1 \mathrm{~h}$ at $4{ }^{\circ} \mathrm{C}$, substrate $(50 \mu \mathrm{L} \mathrm{NBT/BCIP}$ in $100 \mathrm{mM}$ Tris- $\mathrm{HCl}$, $\mathrm{pH} 9.5,5 \mathrm{mM} \mathrm{MgCl}_{2}, 100 \mathrm{mM} \mathrm{NaCl}$ ) was added to the membrane and incubated at $37^{\circ} \mathrm{C}$.

\section{Microscale thermophoresis (MST)}

MST, an immobilization-free method, was used for the characterization of the Nb-MOMP interaction. This technique allows the study of interactions of biomolecules in solution. A NanoTemper Monolith NT.115 instrument (NanoTemper Technologies) was used for the binding experiments, wherein a temperature gradient is formed in glass capillaries by means of an infrared laser. The movement of the biomolecules along this gradient is affected by changes in size or charge and modifications in their hydration shell. For the saturation binding 
experiment, an anti-Campylobacter nanobody was fluorescently labelled via free amino-groups with Dylight 650 NHS Ester (Thermo Fisher Scientific). The labelled nanobody (constant concentration of $32 \mathrm{nM}$ ) was mixed with twofold serial dilutions of MOMP, ranging from $0.3 \mathrm{nM}$ to $5.0 \mu \mathrm{M}$. The interaction of the proteins was measured in $20 \mathrm{mM}$ sodium phosphate buffer $\mathrm{pH} 7.6$ supplemented with $150 \mathrm{mM} \mathrm{NaCl}$ and $0.6 \%$ octyl-POE. The samples were loaded into the glass capillaries (Monolith $^{\mathrm{TM}}$ NT.Automated Standard Treated Capillary Chips), the thermophoresis measurements were performed (MST power $10 \%$ and LED 100\%) and the data were analysed using the NT Analysis software (NanoTemper Technologies). Data were normalized to $\Delta$ Fnorm [\%o] [46]. A competition experiment was used to determine whether an unlabelled nanobody can impede the interaction of the labelled nanobody and the MOMP. In this experiment, the unlabelled nanobody was used at a constant concentration of $10 \mu \mathrm{M}$ and mixed with a twofold serial dilution of MOMP (0.3 nM to $5.0 \mu \mathrm{M})$. Afterwards, the labelled nanobody was added to the suspension at a constant concentration of $32 \mathrm{nM}$. The experiment was further carried out as described above.

\section{Saturation and competition binding assay}

A saturation binding assay was performed using ELISA, to determine the interaction between a constant concentration MOMP $(1 \mu \mathrm{g} / \mathrm{mL})$ and tenfold serial dilutions of His-tagged Nb84, ranging from $5 \times 10^{-7}$ to $5 \times 10^{1} \mu \mathrm{g} /$ $\mathrm{mL}$. In a second experiment, the influence of competitors on this interaction was examined. Therefore MOMP $(1 \mu \mathrm{g} / \mathrm{mL})$ was coated in a 96-well plate, after which serial dilutions (from $5 \times 10^{-7}$ to $5 \times 10^{1} \mu \mathrm{g} / \mathrm{mL}$ ) of streptagged anti-Campylobacter nanobodies, used as competitors, and a constant concentration of His-tagged Nb84 $\left(5 \times 10^{-2} \mu \mathrm{g} / \mathrm{mL}\right)$ were simultaneously added. Bound His-tagged nanobody was detected with a mouse antiHistidine tag monoclonal antibody and goat anti-mouse IgG conjugated to alkaline phosphatase (AP).

\section{Sequence analysis of porA-gene of $C$. jejuni and $C$. coli isolates}

To analyse the genetic variability of MOMP between different Campylobacter strains, the porA-gene was amplified with primers F3 (5'-ATGAAACTAGTTA AACTTAGTTTA-3') and R3 (5'-GAATTTGTAAAGA GCTTGAAG- $3^{\prime}$ ) [47]. A single colony of every isolate was resuspended in $50 \mu \mathrm{L}$ deionized $\mathrm{H}_{2} \mathrm{O}$ and the suspension was frozen at $-80{ }^{\circ} \mathrm{C}$ and subsequently boiled at $95{ }^{\circ} \mathrm{C}$ for $5 \mathrm{~min}$. Of the suspension $1 \mu \mathrm{L}$ was used as a template.

\section{Immunofluorescence microscopy}

Campylobacter jejuni KC40 cells were fixed during 10 min with a final concentration (v/v) of $1.2 \%$ formaldehyde (methanol-stabilized, Merck). Fixed cells were spotted on $0.1 \%$ poly-L-lysine treated glass slides and dried. The microscope slides were treated with 5\% BSA for $15 \mathrm{~min}$, followed by the addition of $30 \mu \mathrm{L}$ anti-Campylobacter nanobodies $(50 \mu \mathrm{g} / \mathrm{mL})$ and incubation for $1 \mathrm{~h}$ at room temperature. The bound nanobodies were detected in two consecutive steps. First, mouse anti-His monoclonal antibodies (1:200) (AbD Serotec) were added and incubated for $1 \mathrm{~h}$ at room temperature. Anti-mouse IgG conjugated to Alexa Fluor 488 (1:250) (Thermo Fisher Scientific) was then added for fluorescent labelling. After $1 \mathrm{~h}$, the slides were washed with PBS and dried. As a negative control, anti-F4 nanobodies [48, 49] were used. In between every step, the glass plates were washed with PBS and dried.

\section{Multimerization of nanobodies}

Selected nanobodies were coupled to $\mathrm{Co}^{2+}$-coated magnetic Dynabeads (Dynabeads ${ }^{\circledR}$ His-Tag Isolation and Pulldown, Thermo Fisher Scientific) to make them multivalent, using the buffers described in the manual. Nanobodies $(24 \mu \mathrm{g})$ were added to $300 \mu \mathrm{g}$ of Dynabeads and the mixture was incubated at room temperature during $10 \mathrm{~min}$ on a roller. Hereafter, the beads were washed three times to remove the unbound nanobodies and the nanobody-coupled beads were stored in pull-down buffer at $4{ }^{\circ} \mathrm{C}$.

Campylobacter jejuni $\mathrm{KC} 40$ cells were harvested from NB2-agar plates with NB2 medium and a suspension with $\mathrm{OD}_{660} 2.0$ was used for the agglutination assay. The bacterial cells and nanobody-coupled beads were mixed in a 1:4 ratio in a final volume of $10 \mu \mathrm{L}$ on a slide. The slides were incubated at room temperature and examined visually and by phase contrast microscopy for agglutination. As a negative control, the agglutination of Campylobacter bacteria in the presence of beads coupled with anti-F4 nanobodies was assessed [48, 49].

\section{Results}

Isolation of anti-Campylobacter nanobodies with a broad specificity

To generate an immune library, an alpaca was immunized with heat-inactivated KC40 bacteria. From this library, 21 Campylobacter-specific nanobodies were obtained after two consecutive panning rounds against an outer membrane fraction of the $C$. jejuni strain KC40. These nanobodies belong to 12 different families (Figure 1) showing less than $80 \%$ identity in their 


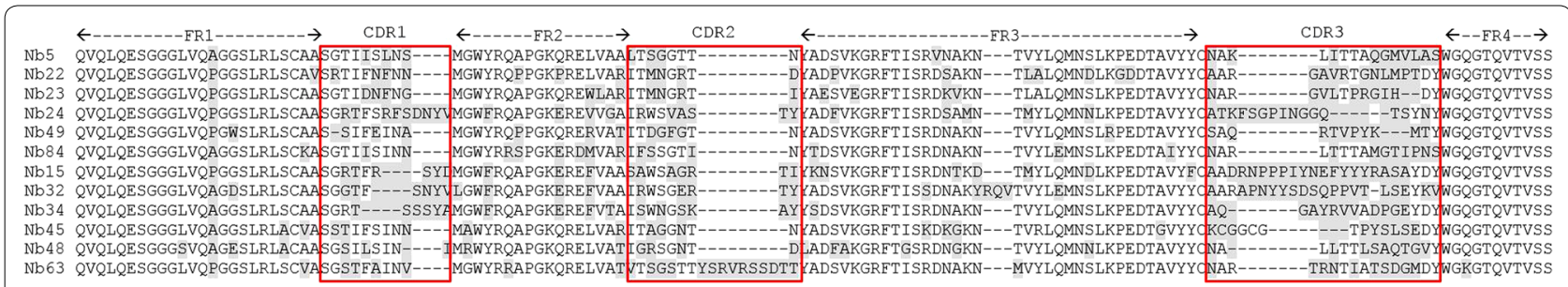

Figure 1 Amino acid sequence alignment of anti-Campylobacter nanobodies selected for their broad specificity. The structural framework regions are indicated by FR1-FR4 and the red boxes specify the CDRs. On the basis of the variation of the amino acid sequence of the CDR3, the nanobodies were divided in twelve unique groups.

complementarity-determining region 3 (CDR3), as defined by Pardon et al. [40]. A significant level of diversity is found among Campylobacter strains isolated from poultry [50]. For this reason, we selected one nanobody from each family and examined whether these display a broad detection range by testing their binding with Campylobacter strains [30,51], belonging to different subtypes (Table 1). Whole-cell ELISA analysis showed that the six anti-Campylobacter nanobodies have a broad specificity range (Additional file 1). They interacted with all 23 tested C. jejuni strains, both from chickens and human patients, and with the 5 tested $C$. coli isolates. These data suggest that these nanobodies recognize conserved antigens on the cell surface of the Campylobacter strains.
Nanobodies interact with folded outer membrane proteins Whole-cell ELISA showed that the six nanobodies with broad specificity recognize epitopes exposed on the bacterial cell surface. ELISA was used to determine whether the nanobodies recognize conformational or linear epitopes (Figure 2). The nanobodies showed strong binding with native outer membrane proteins, while the interaction was significantly reduced after denaturation of the outer membrane proteins. These results indicate that the nanobodies bind to conformational epitopes present on outer membrane proteins.

\section{MOMP is the target of the isolated anti-Campylobacter nanobodies}

To determine the antigens recognized by the six nanobodies with broad specificity, a pull-down experiment

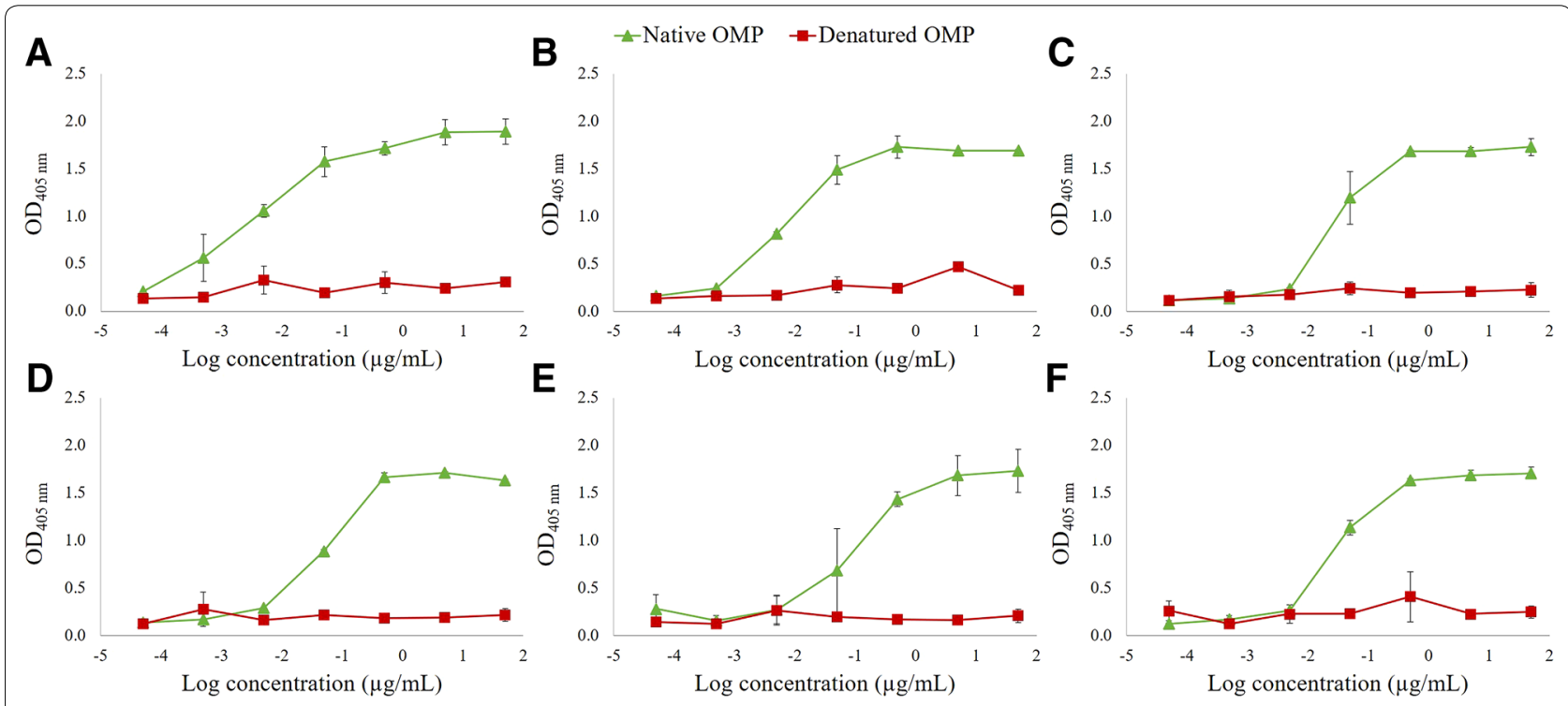

Figure 2 Anti-Campylobacter nanobodies interact with native outer membrane proteins. Serial tenfold dilutions of the nanobodies were used in ELISA to assess the binding with linear or conformational epitopes. OMPs $(1 \mu \mathrm{g} / \mathrm{mL})$ were coated in a 96-well plate and the interaction of His-tagged nanobodies with native, untreated OMP, and with denatured protein extract was measured. Binding of A Nb5, B Nb22, C Nb23, D Nb24, E Nb49 and $\mathbf{F}$ Nb84 was measured. For detection, mouse anti-Histidine tag monoclonal antibody and goat anti-mouse lgG conjugated to alkaline phosphatase were used. The error bars represent the standard deviations. 
with magnetic beads was performed. Complexes with an outer membrane protein were isolated with three of the six nanobodies (Nb5, Nb22 and Nb84). The bound proteins were digested with trypsin and the peptides were analysed by LC-MS/MS. In each case, the amino acid sequences of the peptides corresponded to the MOMP sequence of $C$. jejuni NCTC 11168 (UniProtKB - P80672) (Additional file 2), a porin that is a crucial virulence factor of Campylobacter. The MOMP was subsequently purified from C. jejuni KC40 bacteria and binding with the three nanobodies was confirmed by western blotting. The binding of Nb84 with native MOMP is shown in Figure 3A. The western blot clearly shows a protein band corresponding to native MOMP. The western blot with the nanobodies shows no interaction with the denatured MOMP (Figure 3B). This confirms the interaction with surface-exposed epitopes of MOMP. Similar results were obtained for the five other nanobodies with broad specificity. ELISA further showed that the other nanobodies with less broad specificity also recognize native MOMP (Additional file 3).

\section{Affinity determination and competitive binding assay}

We determined the strength of the interaction between MOMP and the nanobodies $\mathrm{Nb} 5, \mathrm{Nb} 22$ and $\mathrm{Nb} 84$ using microscale thermophoresis (MST). Therefore, the nanobodies were fluorescently labelled and incubated with increasing concentrations of MOMP (Figure 4; Additional file 4). Changes in the thermophoretic properties upon complex formation were plotted, to obtain information on the dissociation constant $\left(\mathrm{K}_{\mathrm{D}}\right.$-value). $\mathrm{Nb22}$ and Nb84 bind MOMP with intermediate nanomolar affinities $\left(K_{D}=118 \pm 48 \mathrm{nM}\right.$ and $K_{D}=422 \pm 159 \mathrm{nM}$, respectively). For $\mathrm{Nb} 5$, it was not possible to determine the dissociation constant because of a high signal to noise ratio.

The specificity of the binding curves was confirmed by adding an excess of the same unlabelled nanobody, which resulted in a loss of the MST signal (Figure 4C). In addition, a competitive MST assay was performed by adding an excess of a different unlabelled nanobody, that can potentially compete with the binding of the labelled nanobody to MOMP. When adding either unlabelled Nb5 or $\mathrm{Nb} 22$, no clear shift in the MST signal, corresponding to
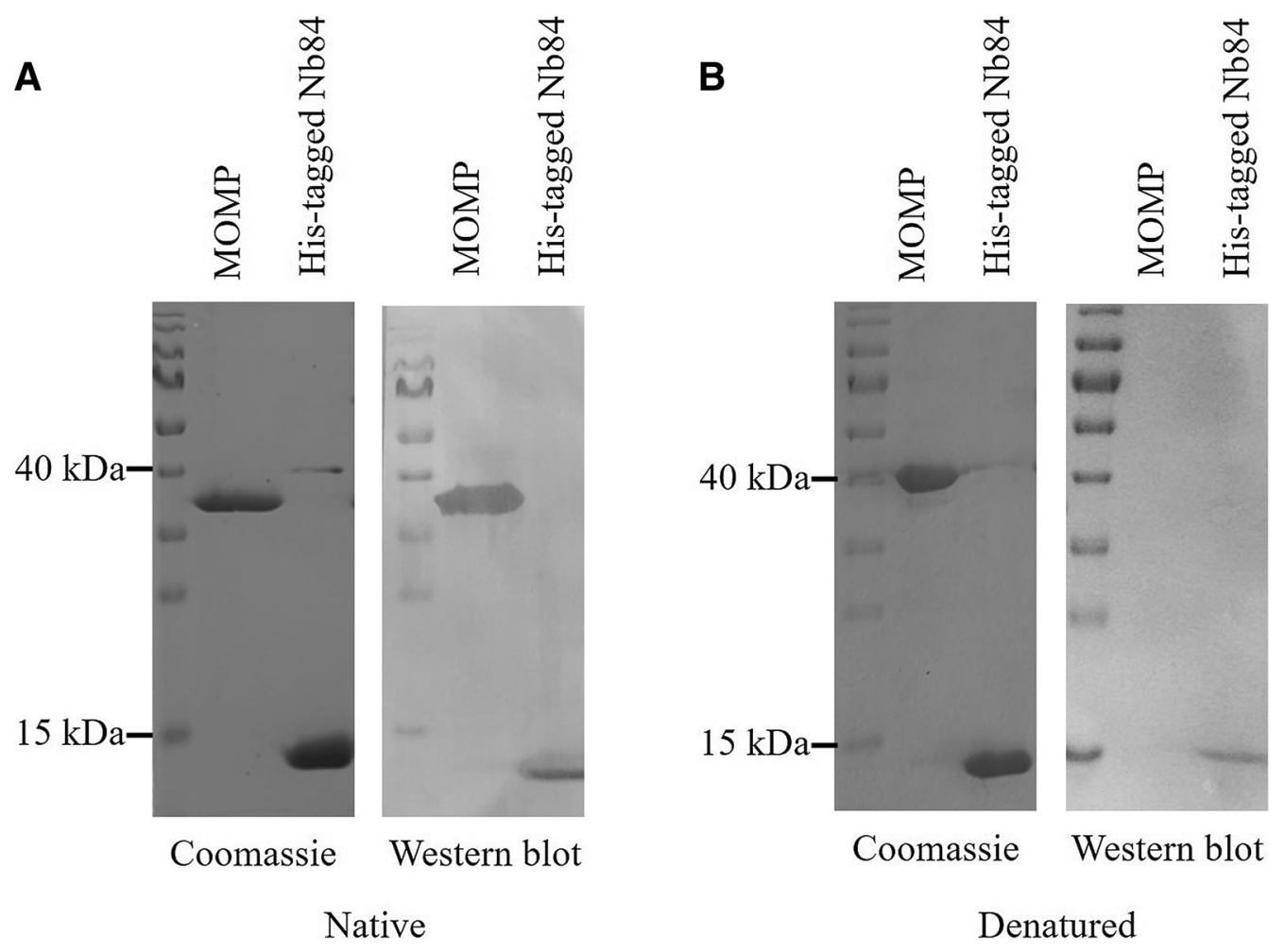

Denatured

Figure 3 Confirmation of the binding of Nb84 with native MOMP. The purified MOMP monomer was subjected to non-denaturing (A) and denaturing (B) SDS-PAGE and transferred to a PVDF membrane for western blotting in which the membrane was first incubated with Nb84. Nb84 shows clear interaction with folded but not with unfolded MOMP. His-tagged Nb84 was added as a positive control. The interaction of the native protein with Nb84 was analysed using a mouse anti-Histidine tag monoclonal antibody and goat anti-mouse lgG conjugated to alkaline phosphatase. The PageRuler ${ }^{\mathrm{TM}}$ prestained protein ladder was used as a molecular weight marker. 


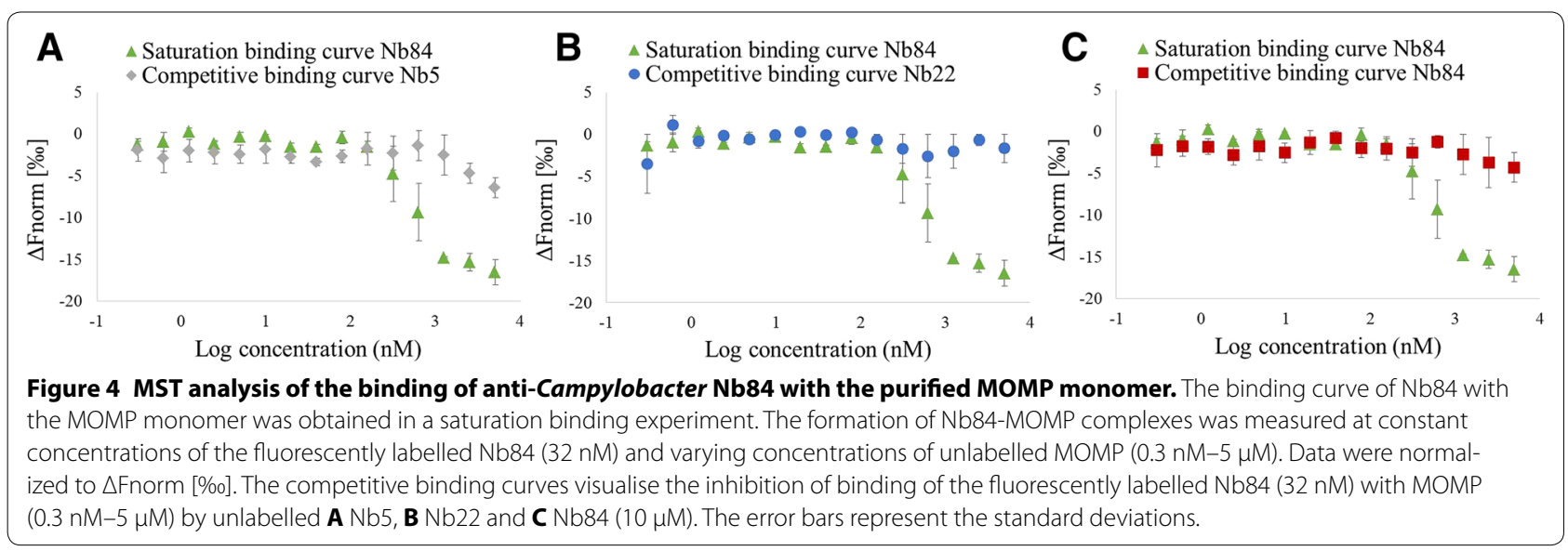

the binding of labelled Nb84 to MOMP, was observed (Figures 4A and B). These data show that these nanobodies do not bind the antigen simultaneously, suggesting that they may recognize the same, adjacent or overlapping epitopes. However, we cannot exclude the possibility that these nanobodies may still bind to different epitopes and interfere with each other's binding by inducing conformational changes.

To confirm the findings of the MST competition assay, we set up a competitive ELISA. The influence of streptagged nanobodies, of the 12 different families, on the binding of His-tagged Nb84 to MOMP was assessed (Figure 5; Additional file 5). Dose-dependent inhibition of the binding was confirmed for nine of the twelve nanobodies. For the other three nanobodies (Nb32, Nb34 and $\mathrm{Nb} 45)$, it was shown that they could bind to MOMP simultaneously with $\mathrm{Nb84}$, which indicates they recognize different epitopes.

\section{Variability in the porA-gene encoding MOMP}

The MOMP of C. jejuni and C. coli is characterised by high genetic diversity. Little variability is observed in the transmembrane domains, in contrast to high variability in the extracellular loops [52]. The MOMP-encoding porA-gene of the $23 \mathrm{C}$. jejuni and the $5 \mathrm{C}$. coli stains was PCR-amplified and sequenced (Additional file 6). Based on the MOMP structure solved by Ferrara et al. [39], the extracellular loops and $\beta$-strands were identified in the sequence. Since the broad specificity range nanobodies bind to the surface of Campylobacter cells, we can assume that they interact with one of the surfaceexposed loops of MOMP. These loops are however most variable amongst the sequenced MOMP genes. Sequence analysis shows that the extracellular loops L3 and L6 are the most conserved, in length and amino acid sequence, making these prime candidates to be recognized by the six nanobodies with a broad specificity range. Mapping of the sequences on the structure of MOMP confirms that the highest variability is located in the extracellular loops,

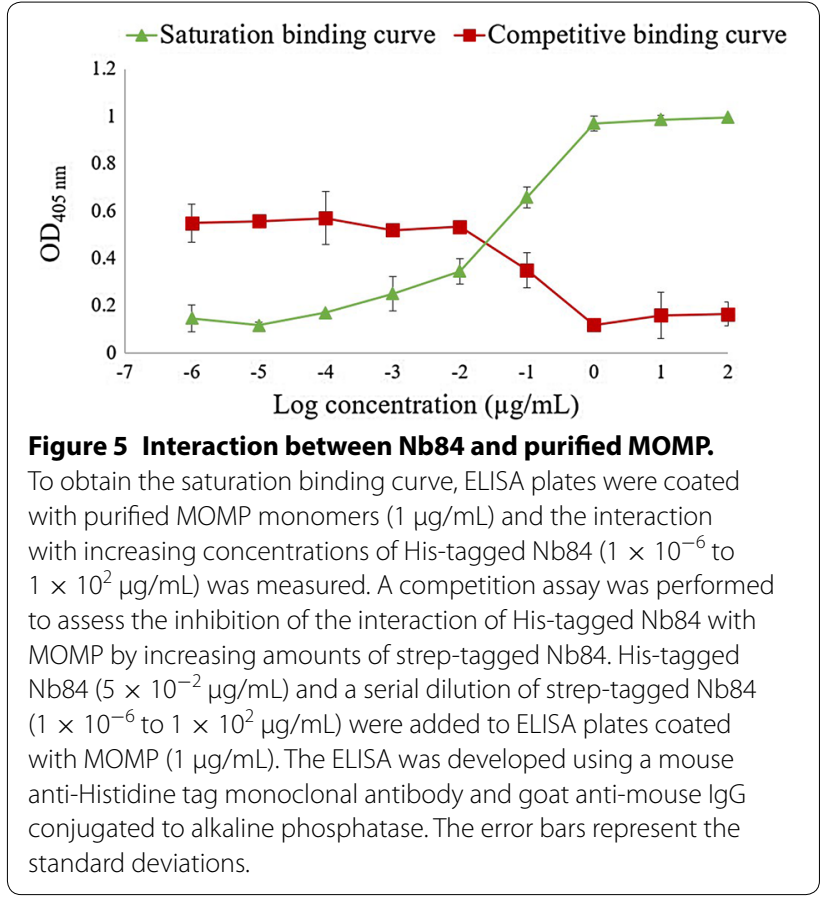

while the sequence in the $\beta$-barrel structure is highly conserved (Additional file 7).

The sequence diversity in L3 and L6 in different $C$. jejuni and C. coli strains was analysed (Additional file 8). The MOMP encoding sequences in the MLSTdb database [53] were used for the analysis of the L6 region. Since the sequence of L3 is not present in the MLSTdb database, sequences were obtained from the NCBI database using Blastp with the porA sequence from $C$. jejuni $\mathrm{KC} 40$ as a query [54]. Comparison of the porA amino acid sequences, showed that the majority $(81.9 \%$ or 1827 out of 2230) of analysed Loop 6 sequences and 92.5\% (620 out of 670) of analysed Loop 3 sequences all carry amino acid substitutions at positions found in the L6 and 
L3 loops of the 28 MOMPs analysed in this study. From our study, we know that these amino acid substitutions in the L3 and L6 loops of MOMPs do not impede nanobody binding. The remaining $18.1 \%$ (403 of 2230) in case of L6 and 7.5\% (50 of 670) encoding L3, contain amino acid changes on other positions. This does not imply that our six nanobodies with broad specificity would not bind these MOMP variants.

\section{Interaction of anti-Campylobacter nanobodies with the bacterial cell surface}

Immunofluorescence microscopy was used to confirm the interaction of $\mathrm{Nb} 22, \mathrm{Nb} 23$ and $\mathrm{Nb} 84$ with the surface of $C$. jejuni KC40 cells (Figure 6). The results show clear fluorescence with the Campylobacter-specific nanobodies, in comparison with an anti-E. coli nanobody that was used as a negative control.

To explore whether the anti-Campylobacter nanobodies could agglutinate living C. jejuni $\mathrm{KC} 40$ cells, the six selected nanobodies were made multivalent, by coupling them to magnetic Dynabeads via their histidine tag. Clear agglutination was observed when $C$. jejuni KC40 cells were added (Figure 7A). Here the results of $\mathrm{Nb} 84$ with $C$. jejuni $\mathrm{KC} 40$ are shown. Beads, coated with an anti-E. coli nanobody, were used as a negative control and caused no visible agglutination of Campylobacter (Figure 7B). Additional negative controls were the Campylobacter bacteria and the beads coated with nanobodies alone (Figures $7 \mathrm{C}$ and $\mathrm{D}$ ). The results confirm that the Campylobacter-specific nanobodies can bind with surface-exposed epitopes of $C$. jejuni $\mathrm{KC} 40$ and agglutinate the latter.

\section{Discussion}

Substantial diversity of Campylobacter strains is found within broiler flocks and broilers are often colonized with multiple strains of $C$. jejuni [55]. Co-colonization by $C$. jejuni and $C$. coli has also been observed $[13,56]$. Phage display technology was used to obtain a nanobodylibrary against the $C$. jejuni strain KC40. Here we selected six anti-Campylobacter nanobodies that interact with the cell surface of 23 different $C$. jejuni isolates derived from a poultry farm, poultry carcasses or faeces of human patients, as well as with 5 C. coli isolates.

Next, MOMP was identified as the antigen recognized by twelve nanobodies, from which six show a broad specificity. Since MOMP is an abundant protein in the outer membrane and since it is highly immunogenic [57], these findings are not surprising. MOMP is an essential porin for Campylobacter bacteria, as deletion of the porA-gene is lethal, and it is a key virulence factor, crucial for colonization [36, 37]. Islam et al. showed that the administration of recombinant MOMP, leads to protection of mice against colonization by heterologous $C$. jejuni strains [58]. Nanobodies targeting MOMP may interfere with its function and reduce colonization. Sequence analysis of the porA-gene of the 28 isolates showed that the extracellular Loop 3 and Loop 6 are the most conserved. These loops are potential candidates to be recognized by the nanobodies. The sequence diversity in these loops in the publicly available por $A$-sequences, was analysed. The results indicate that $92.5 \%$ of the analysed Loop 3 and $81.9 \%$ of the analysed Loop 6 sequences, carry amino acid substitutions at positions also found in the Loop 3 and Loop 6 sequences of the 28 isolates used in this study and do not influence the nanobody binding.

The anti-Campylobacter nanobodies were shown to interact with conformational epitopes on MOMP. Competition experiments showed that nine of the twelve anti-Campylobacter nanobodies could compete with each other's binding to MOMP. This is an indication that they recognize the same or overlapping epitopes. Three of the anti-Campylobacter nanobodies were not able to inhibit the interaction of Nb84 with MOMP, hence they can simultaneously bind with MOMP. For Nb5, Nb22 and Nb84, affinity measurements were performed. Nb22 and $\mathrm{Nb} 84$ were shown to interact with MOMP with highnanomolar affinities. However affinity measurements with $\mathrm{Nb} 5$ gave no consistent results. The binding strength of the nanobodies can presumably be further increased by the generation of a bivalent construct. By using a flexible peptide linker, dimers can be formed by coupling two nanobodies with the same specificity, resulting in higher avidity, or by combining two nanobodies binding different epitopes, creating bi-specific constructs [59].

The monovalent character and the small size of nanobodies, lead to rapid clearance. Multimerization of nanobodies can increase the retention. The results show that multimerization of the anti-Campylobacter nanobodies by non-covalent coupling to magnetic beads, resulted in agglutination of $C$. jejuni cells. Nanobodies can be multimerized by surface-expression on Generally Recognized As Safe (GRAS) organisms [60]. Agglutination typically takes place at high bacterial densities [61]. In the gut agglutination of Campylobacter could promote its removal and reduce colonization [62, 63]. Alternatively, Moor et al. showed that high-avidity IgA promotes the enchained growth of bacterial cells, leading to the formation of clumps. The latter mainly takes place at lower cell densities and leads to an enhanced clearance of the bacteria [61]. Virdi et al. [49] fused nanobodies against F4 fimbriae of enterotoxigenic E. coli (ETEC), with the Fcdomain of porcine IgA. Arabidopsis thaliana seeds were used for the expression of these constructs and passive vaccination with the seeds resulted in the protection of weaned piglets against ETEC-infections. Chicken feed 

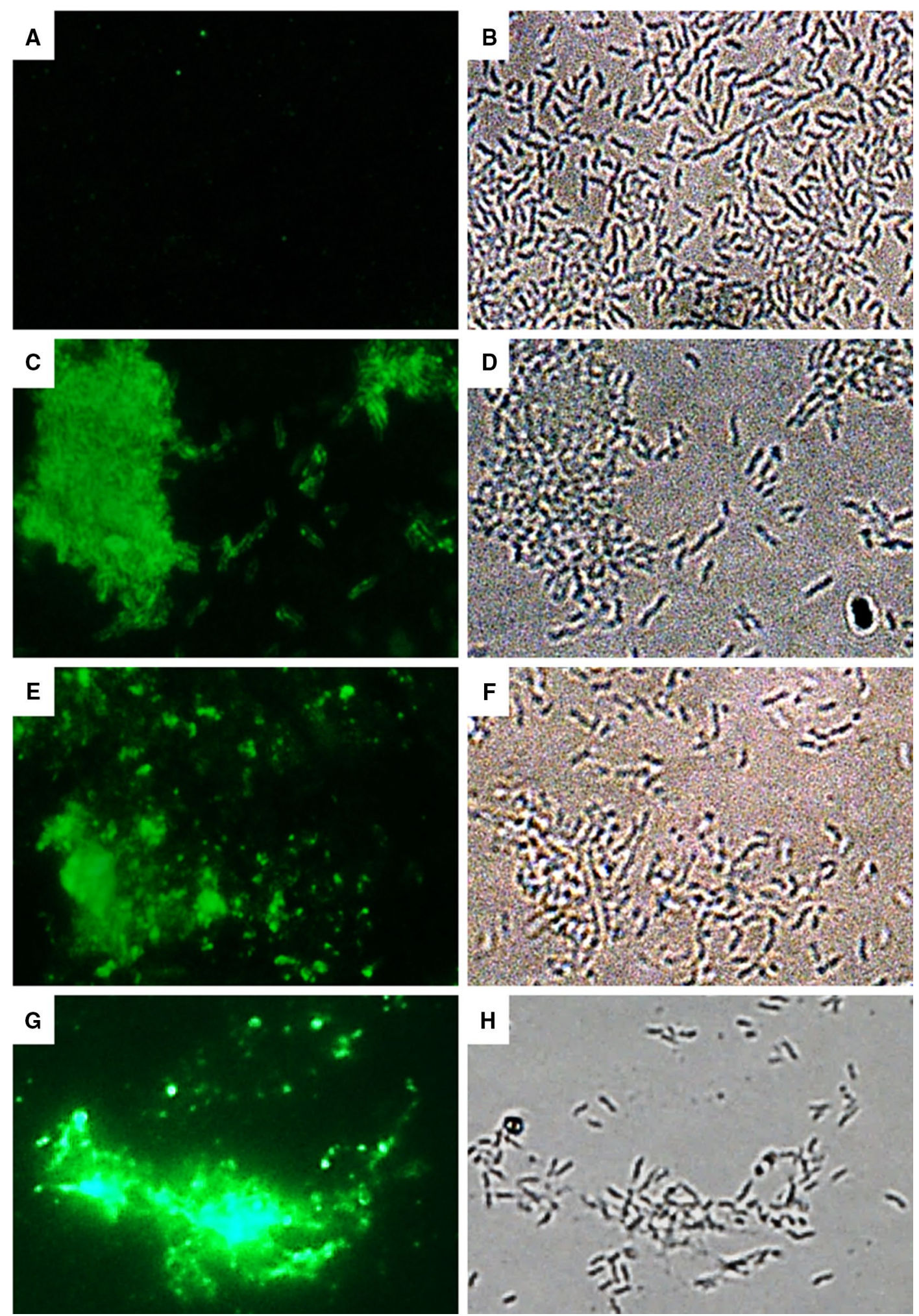

Figure 6 Detection of the interaction of anti-Campylobacter nanobodies and C. jejuni KC40 by immunofluorescence microscopy. The interaction was detected by $(\mathbf{A}, \mathbf{C}, \mathbf{E}, \mathbf{G})$ immunofluorescence microscopy and the $C$. jejuni cells $(\mathbf{B}, \mathbf{D}, \mathbf{F}, \mathbf{H})$ were visualised by bright field microscopy. A, B A nanobody specific for F4-fimbriated enterotoxigenic E. coli shows no binding with the C. jejuni cells. C, D; E, F and $\mathbf{G}, \mathbf{H}$ The anti-Campylobacter nanobodies Nb22, Nb23 and Nb84 respectively, binds specifically with the C. jejuni cells. 

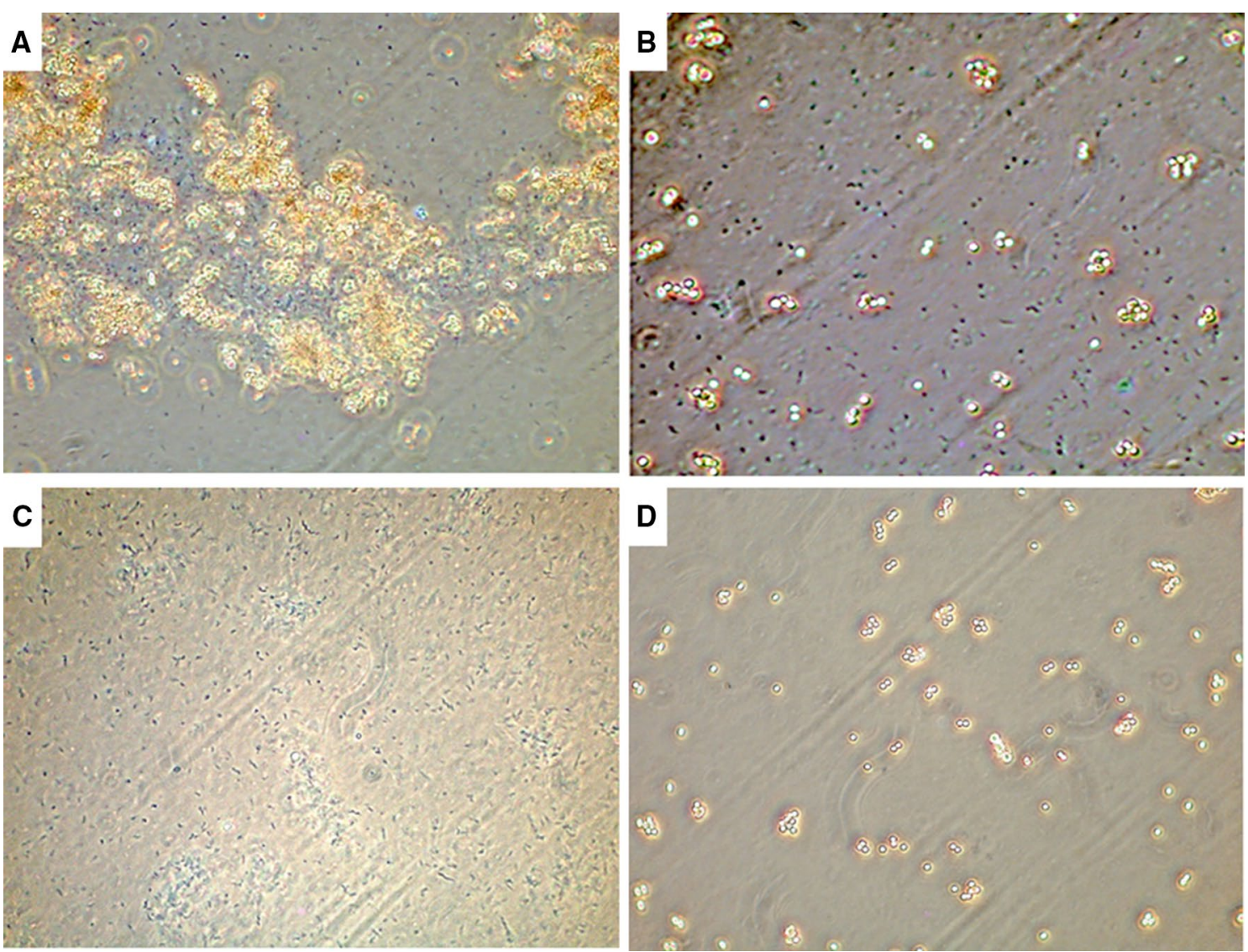

Figure 7 Nanobody-coated beads agglutinate $\mathbf{C}$. jejuni KC40 cells. The His-tagged nanobodies were coupled to magnetic dynabeads, leading to multimerization. A Nb84 coupled to dynabeads causes agglutination of KC40 cells. B As a negative control, dynabeads coated with anti-E. coli nanobodies were mixed with KC40 cells. No agglutination was observed in this case. C The C. jejuni KC40 bacteria and D the beads coated with Nb84. The results were observed by phase contrast microscopy, using a $\times 100$ oil immersion objective.

supplemented with seeds containing anti-MOMP nanobodies, fused to the effector domains of chicken IgA or IgY, may, in a similar way, be used as a therapeutic agent against Campylobacter infection. The work described in this study, forms the basis for the development of such chimeric antibodies. The advantages of seeds include inexpensive production by standard agricultural practices, excellent stability of the antibodies in the seeds and the possible protection of the nanobodies against degradation in the gastrointestinal tract of the chickens [64]. Riazi et al. [65] reported that pentamers of flagellaspecific nanobodies interfere with the motility of $C$. jejuni and lead to the reduction of colonization by $C$. jejuni in the caecum of treated chickens.

In conclusion, we isolated nanobodies against the essential virulence factor MOMP. Since these recognize conserved epitopes, present on C. jejuni and C. coli strains, they could potentially be used in therapy and as a diagnostic tool [49, 65-67].

\section{Additional files}

Additional file 1. Results of the ELISA performed to measure the binding of anti-Campylobacter nanobodies to different Campylobacter isolates. Whole-cell ELISA was used to identify the anti-Campylobacter nanobodies with a broad specificity. C. jejuni isolates from poultry or faeces of human patients, as well as C. coli strains were tested.

Additional file 2. LC-MS/MS identifies the MOMP as a target for the nanobodies. Proteins recognized by the anti-Campylobacter nanobodies were isolated by a pull-down. After digestion of the proteins with trypsin, the peptides were analysed via LC-MS. The five peptides corresponding with the MOMP of C. jejuni NCTC 11168 (UniProtKB - P80672) are specified by the black boxes.

Additional file 3. ELISA to determine the binding of anti-Campylobacter nanobodies to MOMP. Purified MOMP $(1 \mu \mathrm{g} / \mathrm{mL})$ was coated and nanobodies were subsequently added at a concentration of $50 \mathrm{\mu g} /$ $\mathrm{mL}$. Mouse anti-Histidine tag monoclonal antibody and goat anti-mouse IgG conjugated to alkaline phosphatase were used for the development of the ELISA. The experiment was performed in duplicate and the mean of the obtained results is shown. The error bars represent the standard deviations. As a negative control, an anti-F4 nanobody was used. 


\begin{abstract}
Additional file 4. Binding curve of $\mathrm{Nb22}$ with purified MOMP obtained in a saturation binding experiment using MST analysis. The formation of Nb22-MOMP complexes was measured at constant concentrations of the fluorescently labelled Nb22 $(32 \mathrm{nM})$ and varying concentrations of unlabelled MOMP $(0.3 \mathrm{nM}$ to $5 \mu \mathrm{M})$. Data were normalized to $\Delta$ Fnorm [\%o]. The error bars represent the standard deviations.
\end{abstract}

Additional file 5. ELISA to assess the interaction between Campylobacter-specific nanobodies and purified MOMP. The saturation binding curve of the interaction between coated MOMP $(1 \mu \mathrm{g} / \mathrm{mL})$ and a His-tagged nanobody $\left(1 \times 10^{-6}\right.$ to $\left.1 \times 10^{2} \mu \mathrm{g} / \mathrm{mL}\right)$ was obtained via ELISA. The dose-dependent inhibitory effect of a strep-tagged nanobody $\left(1 \times 10^{-6}\right.$ to $\left.1 \times 10^{2} \mu \mathrm{g} / \mathrm{mL}\right)$ on the interaction between His-tagged Nb84 $\left(5.10^{-2} \mu \mathrm{g} / \mathrm{mL}\right)$ and MOMP $(1 \mu \mathrm{g} / \mathrm{mL})$, is demonstrated in the competition binding curve. Inhibition by strep-tagged (A) Nb5, (B) Nb22, (C) Nb23, (D) Nb24, (E) Nb49, (F) 84, (G) Nb15, (H) Nb32, (I) Nb34, (J) Nb45, (K) Nb48 and (L) Nb63, was assessed. The ELISA was developed with mouse antiHistidine tag monoclonal antibody and goat anti-mouse lgG conjugated to alkaline phosphatase. The error bars represent the standard deviations.

\section{Additional file 6. Alignment of amino acid sequences of the} MOMP-encoding porA-gene. The porA gene of the C. jejuni and C. coli isolates (Table 1) was amplified using PCR and aligned, using C. jejuni KC40 as a reference strain, to identify conserved regions. The PCR was performed with the primers F3 (5'-ATGAAACTAGTTAAACTTAGTTTA-3') and R3 (5'-GAATTTGTAAAGAGCTTGAAG-3'). External loops are labelled from $L 1$ to $L 7$ and $\beta$-strands are underlined, based on the MOMP structure determined by Ferrara et al. [39]. Loops L3 and L6 are the most conserved in sequence and number of amino acids.

Additional file 7. Sequence conservation of porA gene mapped on MOMP crystal structure. The sequence conservation in the alignment of the porA gene of 28 Campylobacter isolates (Table 1), is visualised on the surface of MOMP. Blue corresponds to high amino acid sequence conservation and white with low conservation. High variability is observed in the extracellular loops, while the sequence encoding the transmembrane $\beta$-barrel is highly conserved. (Left) side view and (right) top view.

Additional file 8. Sequence variability in L3 and L6 of the MOMP encoding sequences from $\boldsymbol{C}$. jejuni and $\boldsymbol{C}$. coli strains. For the analysis of $L 3$, sequences were obtained from the NCBI database using Blastp with the MOMP encoding sequence of C. jejuni KC40 as a query. The analysis of L6, was based on porA sequences in the MLSTdb database.

\section{Abbreviations}

BSA: bovine serum albumin; CDR: complementarity-determining region; His: histidine; MST: microscale thermophoresis; Nb: nanobody; NB2: Nutrient Broth Nr.2; PBS: phosphate-buffered saline; PVDF: polyvinylidene difluoride.

\section{Competing interests}

The authors declare that they have no competing interests.

\section{Authors' contributions}

HDG, JPH, FP, FH and AM conceived the study. JE and GGH immunized the alpaca and isolated Campylobacter specific nanobodies. CV purified the antiCampylobacter nanobodies and selected those with broad specificity. IDdO and CV identified the antigen of the nanobodies and CV further characterised the interactions between the nanobodies and the MOMP. DV performed the LC-MS experiments. KM helped with the MST experiments and the analysis of the obtained results. CV, HDG and JPH interpreted the results and CV wrote the article. All authors read and approved the final manuscript.

\section{Acknowledgements}

We thank Dr. Delphine Martiny (Department of Microbiology, Iris-lab Brussels) for providing us with human C. jejuni strains and Dr. Marc Heyndrickx (the Institute for Agricultural and Fisheries Research, Technology and Food Science Unit-Food safety, ILVO) for providing C. jejuni and C. coli strains.

\section{Funding}

The research that yielded these results, was funded by the Belgian Federal Public Service of Health, Food Chain Safety and Environment through the Contract RF 13/6272 CampyNanoCure. KM is funded by an FWO postdoctoral fellowship.

\section{Author details}

${ }^{1}$ Structural Molecular Microbiology, VIB, Pleinlaan 2, 1050 Brussels, Belgium. ${ }^{2}$ Structural Biology Brussels, Vrije Universiteit Brussel, Pleinlaan 2, 1050 Brussels, Belgium. ${ }^{3}$ Genetische Virologie, Vrije Universiteit Brussel, Pleinlaan 2, 1050 Brussels, Belgium. ${ }^{4}$ Department of Pathology, Bacteriology and Avian Diseases, Faculty of Veterinary Medicine, Ghent University, Salisburylaan 133, 9820 Merelbeke, Belgium. ${ }^{5}$ VIB Nanobody Service Facility, Vrije Universiteit Brussel, Pleinlaan 2, 1050 Brussels, Belgium. ${ }^{6}$ Faculty of Medicine and de Duve Institute, Université Catholique de Louvain, Avenue Hippocrate 74, 1200 Brussels, Belgium.

\section{Publisher's Note}

Springer Nature remains neutral with regard to jurisdictional claims in published maps and institutional affiliations.

Received: 25 July 2017 Accepted: 19 November 2017

Published online: 08 December 2017

\section{References}

1. Ruiz-Palacios GM (2007) The health burden of Campylobacter infection and the impact of antimicrobial resistance: playing chicken. Clin Infect Dis 44:701-703

2. Pires $S M$, Fischer-Walker CL, Lanata CF, Devleesschauwer B, Hall AJ, Kirk MD, Duarte ASR, Black RE, Angulo FJ (2015) Aetiology-specific estimates of the global and regional incidence and mortality of diarrhoeal diseases commonly transmitted through food. PLoS One 10:e0142927

3. Waage AS, Vardund T, Lund V, Kapperud G (1999) Detection of small numbers of Campylobacter jejuni and Campylobacter coli cells in environmental water, sewage, and food samples by a seminested PCR assay. Appl Environ Microbiol 65:1636-1643

4. Coker AO, Isokpehi RD, Thomas BN, Amisu KO, Larry OC (2002) Human campylobacteriosis in developing countries. Emerg Infect Dis 8:237-244

5. Moore JE, Corcoran D, Dooley JSG, Fanning S, Lucey B, Matsuda M, McDowell DA, Mégraud F, Millar BC, O'Mahony R, O'Riordan L, O'Rourke M, Rao JR, Rooney PJ, Sails A, Whyte P (2005) Campylobacter. Vet Res 36:351-382

6. Young KT, Davis LM, Dirita VJ (2007) Campylobacter jejuni: molecular biology and pathogenesis. Nat Rev Microbiol 5:665-679

7. Hahn AF (1998) Guillain-Barré syndrome. Lancet 352:635-641

8. Nachamkin I, Allos BM, Ho T (1998) Campylobacter species and GuillainBarré syndrome. Clin Microbiol Rev 11:555-567

9. Horrocks SM, Anderson RC, Nisbet DJ, Ricke SC (2009) Incidence and ecology of Campylobacter jejuni and coli in animals. Anaerobe 15:18-25

10. Corry JE, Atabay HI (2001) Poultry as a source of Campylobacter and related organisms. Symp Ser Soc Appl Microbiol 90:96S-114S

11. Thibodeau A, Fravalo P, Yergeau É, Arsenault J, Lahaye L, Letellier A (2015) Chicken caecal microbiome modifications induced by Campylobacter jejuni colonization and by a non-antibiotic feed additive. PLoS One 10:e0131978

12. Beery JT, Hugdahl MB, Doyle MP (1988) Colonization of gastrointestinal tracts of chicks by Campylobacter jejuni. Appl Environ Microbiol $54: 2365-2370$

13. EFSA (2010) Scientific report of EFSA: analysis of the baseline survey on the prevalence of Campylobacter in broiler batches and of Campylobacter and Salmonella on broiler carcasses in the EU, 2008. EFSA J 8:1503

14. Herman L, Heyndrickx M, Grijspeerdt K, Vandekerchove D, Rollier I, De Zutter $L$ (2003) Routes for Campylobacter contamination of poultry meat : 
epidemiological study from hatchery to slaughterhouse. Epidemiol Infect 131:1169-1180

15. Hermans D, Pasmans F, Messens W, Martel A, Van Immerseel F, Rasschaert G, Heyndrickx M, Van Deun K, Haesebrouck F (2012) Poultry as a host for the zoonotic pathogen Campylobacter jejuni. Vector Borne Zoonotic Dis 12:89-98

16. Messens W, Hartnett E, Gellynck X, Viaene J, Halet D, Herman L, Grijspeerdt K (2007) Quantitative risk assessment of human campylobacteriosis through the consumption of chicken meat in Belgium. In: XVIII European symposium on the quality of poultry meat and XII European symposium on the quality of eggs and egg products. 167-168

17. Newell DG, Elvers KT, Dopfer D, Hansson I, Jones P, James S, Gittins J, Stern NJ, Davies R, Connerton I, Pearson D, Salvat G, Allen VM (2011) Biosecurity-based interventions and strategies to reduce Campylobacter spp. on poultry farms. Appl Environ Microbiol 77:8605-8614

18. Lin J (2009) Novel approaches for Campylobacter control in poultry. Foodborne Pathog Dis 6:755-765

19. Wagenaar JA, Mevius DJ, Havelaar AH (2006) Campylobacter in primary animal production and control strategies to reduce the burden of human campylobacteriosis. Rev Sci Tech 25:581-594

20. Moore JE, Barton MD, Blair IS, Corcoran D, Dooley JSG, Fanning S, Kempf I, Lastovica AJ, Lowery CJ, Matsuda M, McDowell DA, McMahon A, Millar BC, Rao JR, Rooney PJ, Seal BS, Snelling WJ, Tolba O (2006) The epidemiology of antibiotic resistance in Campylobacter. Microbes Infect 8:1955-1966

21. Phillips I, Casewell M, Cox T, De Groot B, Friis C, Jones R, Nightingale C, Preston R, Waddell J (2004) Does the use of antibiotics in food animals pose a risk to human health? A critical review of published data. J Antimicrob Chemother 53:28-52

22. Bratz K, Gölz G, Janczyk P, Nöckler K, Alter T (2015) Analysis of in vitro and in vivo effects of probiotics against Campylobacter spp. Berl Munch Tierarztl Wochenschr 128:155-162

23. Hermans D, Martel A, Van Deun K, Verlinden M, Van Immerseel F, Garmyn A, Messens W, Heyndrickx M, Haesebrouck F, Pasmans F (2010) Intestinal mucus protects Campylobacter jejuni in the ceca of colonized broiler chickens against the bactericidal effects of medium-chain fatty acids. Poult Sci 89:1144-1155

24. Hermans D, Van Deun K, Messens W, Martel A, Van Immerseel F, Haesebrouck F, Rasschaert G, Heyndrickx M, Pasmans F (2011) Campylobacter control in poultry by current intervention measures ineffective: urgent need for intensified fundamental research. Vet Microbiol 152:219-228

25. Wagenaar JA, Van Bergen MAP, Mueller MA, Wassenaar TM, Carlton RM (2005) Phage therapy reduces Campylobacter jejuni colonization in broilers. Vet Microbiol 109:275-283

26. Line JE, Svetoch EA, Eruslanov BV, Perelygin WV, Mitsevich EV, Mitsevich IP, Levchuk VP, Svetoch OE, Seal BS, Siragusa GR, Stern NJ (2008) Isolation and purification of enterocin E-760 with broad antimicrobial activity against gram-positive and gram-negative bacteria. Antimicrob Agents Chemother 52:1094-1100

27. Sahin O, Zhang Q, Meitzler JC, Harr BS, Morishita TY, Mohan R (2001) Prevalence, antigenic specificity, and bactericidal activity of poultry anti-Campylobacter maternal antibodies. Appl Environ Microbiol 67:3951-3957

28. Sahin O, Luo N, Huang S, Zhang Q (2003) Effect of Campylobacter-specific maternal antibodies on Campylobacter jejuni colonization in young chickens. Appl Environ Microbiol 69:5372-5379

29. Tsubokura K, Berndtson E, Bogstedt A, Kaijser B, Kim M, Ozeki M (1997) Oral administration of antibodies as prophylaxis and therapy in Campylobacter jejuni-infected chickens. Clin Exp Immunol 108:451-455

30. Hermans D, Van Steendam K, Verbrugghe E, Verlinden M, Martel A, Seliwiorstow T, Heyndrickx M, De Zutter L, Deforce D, Pasmans F (2014) Passive immunization to reduce Campylobacter jejuni colonization and transmission in broiler chickens. Vet Res 45:27

31. Hamers-Casterman C, Atarhouch T, Muyldermans S, Robinson G, Hamers C, Bajyana S, Bendahman N, Hamers R (1993) Naturally occurring antibodies devoid of light chains. Nature 363:446-448

32. Harmsen MM, De Haard HJ (2007) Properties, production, and applications of camelid single-domain antibody fragments. Appl Microbiol Biotechnol 77:13-22

33. Muyldermans S, Baral TN, Retamozzo VC, De Baetselier P, De Genst E, Kinne J, Leonhardt H, Magez S, Nguyen VK, Revets H, Rothbauer U,
Stijlemans B, Tillib S, Wernery U, Wyns L, Hassanzadeh-Ghassabeh G, Saerens D (2009) Camelid immunoglobulins and nanobody technology. Vet Immunol Immunopathol 128:178-183

34. Rubinchik S, Seddon A, Karlyshev AV (2012) Molecular mechanisms and biological role of Campylobacter jejuni attachment to host cells. Eur J Microbiol Immunol (Bp) 2:32-40

35. Al-Adwani SR, Crespo R, Shah DH (2013) Production and evaluation of chicken egg-yolk-derived antibodies against Campylobacter jejuni colonization-associated proteins. Foodborne Pathog Dis 10:624-631

36. Mahdavi J, Pirinccioglu N, Oldfield NJ, Carlsohn E, Stoof J, Aslam A, Self T, Cawthraw SA, Petrovska L, Colborne N, Sihlbom C, Borén T, Wooldridge KG, Ala'Aldeen DAA (2014) A novel O-linked glycan modulates Campylobacter jejuni major outer membrane protein-mediated adhesion to human histo-blood group antigens and chicken colonization. Open Biol 4:130202

37. Wu Z, Periaswamy B, Sahin O, Yaeger M, Plummer P, Zhai W, Shen Z, Dai L, Chen SL, Zhang Q (2016) Point mutations in the major outer membrane protein drive hypervirulence of a rapidly expanding clone of Campylobacter jejuni. Proc Natl Acad Sci U S A 113:10690-10695

38. Dé E, Jullien M, Labesse G, Pagès JM, Molle G, Bolla JM (2000) MOMP (major outer membrane protein) of Campylobacter jejuni; a versatile poreforming protein. FEBS Lett 469:93-97

39. Ferrara LGM, Wallat GD, Moynié L, Dhanasekar NN, Aliouane S, AcostaGutiérrez S, Pagès JM, Bolla JM, Winterhalter M, Ceccarelli M, Naismith JH (2016) MOMP from Campylobacter jejuni is a trimer of 18-stranded $\beta$-barrel monomers with a $\mathrm{Ca}^{2+}$ ion bound at the constriction zone. J Mol Biol 428:4528-4543

40. Pardon E, Laeremans T, Triest S, Rasmussen SGF, Wohlköning A, Ruf A, Muyldermans S, Hol WGJ, Kobilka BK, Steyaert J (2014) A general protocol for the generation of nanobodies for structural biology. Nat Protoc 9:674-693

41. Arbabi Ghahroudi M, Desmyter A, Wyns L, Hamers R, Muyldermans S (1997) Selection and identification of single domain antibody fragments from camel heavy-chain antibodies. FEBS Lett 414:521-526

42. Conrath KE, Lauwereys M, Galleni M, Matagne A, Frère JM, Kinne J, Wyns $L$, Muyldermans $S$ (2001) $\beta$-Lactamase inhibitors derived from singledomain antibody fragments elicited in the Camelidae. Antimicrob Agents Chemother 45:2807-2812

43. Dagert M, Ehrlich SD (1979) Prolonged incubation in calcium chloride improves the competence of Escherichia coli cells. Gene 6:23-38

44. Hobb RI, Fields JA, Burns CM, Thompson SA (2009) Evaluation of procedures for outer membrane isolation from Campylobacter jejuni. Microbiology 155:979-988

45. Arts IS, Vertommen D, Baldin F, Laloux G, Collet JF (2016) Comprehensively characterizing the thioredoxin interactome in vivo highlights the central role played by this ubiquitous oxidoreductase in redox control. Mol Cell Proteom 15:2125-2140

46. Shang $X$, Marchioni F, Sipes N, Evelyn CR, Jerabek-Willemsen M, Duhr S, Seibel W, Wortman M, Zheng Y (2012) Rational design of small molecule inhibitors targeting RhoA subfamily Rho GTPases. Chem Biol 19:699-710

47. Z Zhang Q, Meitzler JC, Huang S, Morishita T (2000) Sequence polymorphism, predicted secondary structures, and surface-exposed conformational epitopes of Campylobacter major outer membrane protein. Infect Immun 68:5679-5689

48. Moonens K, Van Den Broeck I, Okello E, Pardon E, De Kerpel M, Remaut $H$, De Greve H (2015) Structural insight in the inhibition of adherence of F4 fimbriae producing enterotoxigenic Escherichia coli by llama single domain antibodies. Vet Res 46:14

49. Virdi V, Coddens A, De Buck S, Millet S, Goddeeris BM, Cox E, De Greve H, Depicker A (2013) Orally fed seeds producing designer IgAs protect weaned piglets against enterotoxigenic Escherichia coli infection. Proc Natl Acad Sci U S A 110:11809-11814

50. Rivoal K, Ragimbeau C, Salvat G, Collin P, Ermel G (2005) Genomic diversity of Campylobacter coli and Campylobacter jejuni isolates recovered from free-range broiler farms and comparison with isolates of various origins. Appl Environ Microbiol 71:6216-6227

51. Najdenski H, Heyndrickx M, Herman L, Messens W (2008) Fla-DGGE analysis of Campylobacter jejuni and Campylobacter coli in cecal samples of broilers without cultivation. Vet Microbiol 127:196-202 
52. Cody AJ, Maiden MJC, Dingle KE (2009) Genetic diversity and stability of the porA allele as a genetic marker in human Campylobacter infection. Microbiology 155:4145-4154

53. Campylobacter Multilocus Sequence Typing website. https://pubmlst. org/campylobacter/. Accessed 23 Oct 2017

54. National Center for Biotechnology Information. https://blast.ncbi.nlm.nih. gov/Blast.cgi?PAGE=Proteins. Accessed 23 Oct 2017

55. Höök H, Fattah MA, Ericsson H, Vågsholm I, Danielsson-Tham ML (2005) Genotype dynamics of Campylobacter jejuni in a broiler flock. Vet Microbiol 106:109-117

56. Kudirkiene E, Malakauskas M, Malakauskas A, Bojesen AM, Olsen JE (2010) Demonstration of persistent strains of Campylobacter jejuni within broiler farms over a 1-year period in Lithuania. J Appl Microbiol 108:868-877

57. Huang S, Sahin O, Zhang Q (2007) Infection-induced antibodies against the major outer membrane protein of Campylobacter jejuni mainly recognize conformational epitopes. FEMS Microbiol Lett 272:137-143

58. Islam A, Raghupathy R, Albert MJ (2010) Recombinant PorA, the major outer membrane protein of Campylobacter jejuni, provides heterologous protection in an adult mouse intestinal colonization model. Clin Vaccine Immunol 17:1666-1671

59. Saerens D, Ghassabeh GH, Muyldermans S (2008) Single-domain antibodies as building blocks for novel therapeutics. Curr Opin Pharmacol 8:600-608

60. Hultberg A, Tremblay DM, de Haard H, Verrips T, Moineau S, Hammarström L, Marcotte H (2007) Lactobacilli expressing llama VHH fragments neutralise Lactococcus phages. BMC Biotechnol 7:58

61. Moor K, Diard M, Sellin ME, Felmy B, Wotzka SY, Toska A, Bakkeren E, Arnoldini M, Bansept F, Dal Co A, Völler T, Minola A, Fernandez-Rodriguez B, Agatic G, Barbieri S, Piccoli L, Casiraghi C, Corti D, Lanzavecchia A, Regoes RR, Loverdo C, Stocker R, Brumley DR, Hardt WD, Slack E (2017) High-avidity lgA protects the intestine by enchaining growing bacteria. Nature 544:498-502
62. Roche AM, Richard AL, Rahkola JT, Janoff EN, Weiser JN (2015) Antibody blocks acquisition of bacterial colonization through agglutination. Mucosal Immunol 8:176-185

63. Shoaf-Sweeney KD, Larson CL, Tang X, Konkel ME (2008) Identification of Campylobacter jejuni proteins recognized by maternal antibodies of chickens. Appl Environ Microbiol 74:6867-6875

64. Zimmermann J, Saalbach I, Jahn D, Giersberg M, Haehnel S, Wedel J Macek J, Zoufal K, Glünder G, Falkenburg D, Kipriyanov SM (2009) Antibody expressing pea seeds as fodder for prevention of gastrointestinal parasitic infections in chickens. BMC Biotechnol 9:79

65. Riazi A, Strong PCR, Coleman R, Chen W, Hirama T, van Faassen H, Henry M, Logan SM, Szymanski CM, MacKenzie R, Ghahoudi MA (2013) Pentavalent single-domain antibodies reduce Campylobacter jejuni motility and colonization in chickens. PLoS One 8:e83928

66. De Meyer T, Muyldermans S, Depicker A (2014) Nanobody-based products as research and diagnostic tools. Trends Biotechnol 32:263-270

67. Deckers N, Saerens D, Kanobana K, Conrath K, Wernery U, Vercruysse J, Muyldermans S, Dorny P (2009) Nanobodies, a promising tool for speciesspecific diagnosis of Taenia solium cysticercosis. Int J Parasitol 39:625-633

68. Sambrook J, Fritsch EF, Maniatis T (1989) Molecular cloning: a laboratory manual. Cold Spring Harbor Laboratory Press, New York

69. Meselson M, Yuan R (1968) DNA restriction enzyme from E. coli. Nature 217:1110-1114

70. Zell R, Fritz HJ (1987) DNA mismatch-repair in Escherichia coli counteracting the hydrolytic deamination of 5-methyl-cytosine residues. EMBO J 6:1809-1815

\section{Submit your next manuscript to BioMed Central and we will help you at every step:}

- We accept pre-submission inquiries

- Our selector tool helps you to find the most relevant journal

- We provide round the clock customer support

- Convenient online submission

- Thorough peer review

- Inclusion in PubMed and all major indexing services

- Maximum visibility for your research

Submit your manuscript at www.biomedcentral com/submit

(OioMed Central 